\title{
Experimental study of an inclined flat plate-type solar water distillation system
}

\author{
U. Sahoo ${ }^{1,2^{*}}$, S. K. Singh ${ }^{1}$, I. Barbate ${ }^{1}$, R. Kumar ${ }^{2}$ and P. C. Pant ${ }^{1}$
}

\begin{abstract}
Flat plate-type solar water distillation (FPSWD) is having importance for providing hot water and drinking water simultaneously to households in rural areas or small community/hotels. It utilizes solar radiation to heat the water, produce fresh water out of the saline or brackish water, and also produce hot water. The paper is focused on field performance of inclined FPSWD for domestic and commercial applications. Field Performance data of inclined FPSWD has been recorded during summer and winter. It observed that on Solar Global Radiation $6.2 \mathrm{kWh} / \mathrm{m}^{2}$, maximum output of distilled water generation achieved $6.03 \mathrm{l} /$ day per $\mathrm{m}^{2}$ at ambient temperature of $23^{\circ} \mathrm{C}$ within $8-9 \mathrm{~h}$.
\end{abstract}

Keywords: Solar energy, Solar distillation, Fresh water

\section{Background}

India's huge and growing population is putting a severe strain on all the natural sources of country. Most water resources are contaminated by sewage and agricultural runoff. India has made progress in supply of drinking water to people, but gross disparity in coverage exists across the country. Although access to drinking water has increased, still about $21 \%$ of communicable diseases in India are related to unsafe water as per World Bank estimation. It is true that providing drinking water to such a large population is an enormous challenge. It is estimated that around 37.7 million Indians are affected by waterborne diseases annually, and one million children are estimated to die of diarrhea. The average availability of water is reducing steadily with the growing population, and it is estimated that by 2020 India will become a water-stressed nation. Ground water is the major source of water in our country with $85 \%$ of the population dependent on it (http://www.angelfire.com/bc/nihhrrc/documents/ fresh.html; http://www.wateraid.org/ /media/Publications/drinking-water-quality-rural-india.pdf). Water org's program in India provides safe drinking water

\footnotetext{
*Correspondence: uk.sec.mnre@gmail.com

${ }^{1}$ National Institute of Solar Energy, Ministry of New and Renewable Energy, Govt. of India, Faridabad Road, Gurgaon 122003, Haryana, India Full list of author information is available at the end of the article
}

and adequate sanitation facility to the families living in rural and urban Indian communities in 11 states and one Union Territory (UT), i.e., Andhra Pradesh, Pondicherry (UT), Madhya Pradesh, Maharashtra, Rajasthan, Bihar, Chhattisgarh, Odisha, West Bengal, Assam, Karnataka, and Tamilnadu.

\section{Scope of solar distillation in India}

India being a tropical country is blessed with good sunshine with most of the parts receiving global solar radiation of 4-7.5 kWh per sq.m per day. Around 250-320 sunny days are available in a year to operate solar distillation system (Ministry of New and Renewable Energy 2011; Policy phase-I and phase-II 2011-12). Conventional desalination systems (i.e., multistage flash, multi-effect dehumidification, and reverse osmosis) are expensive and also consume huge amount of electricity for their operation to produce drinking water. Solar distillation is one of the most prominent solution for production of safe drinking water without conventional energy. Solar distillation have a good chance of success in India for lower capabilities, which are more than 10-20 km away from the source of fresh water and where salinity of water is more than $10,000 \mathrm{ppm}$ (Gomkale 1988). The FPSWD system can operate in these regions to produce safe drinking water. This paper presents an experimental investigation on FPSWD which gives higher efficiency.

\section{Springer}

(c) 2016 Sahoo et al. This article is distributed under the terms of the Creative Commons Attribution 4.0 International License (http://creativecommons.org/licenses/by/4.0/), which permits unrestricted use, distribution, and reproduction in any medium, provided you give appropriate credit to the original author(s) and the source, provide a link to the Creative Commons license, and indicate if changes were made. 


\section{System description}

A single-effect conventional solar still is an air tight basin that contains saline water (i.e., feed water). It is enclosed by a transparent top cover, usually of glass which allows incident solar radiation to pass through. The inner surface of the basin is usually blackened to increase the efficiency of the system by absorbing more of the incident solar radiation (Tiwari et al. 2003). A multiple wick bedtype solar still with condenser arrangement gives higher output than simple traditional solar still (Reddy et al. 1983). The multi-wick solar still is most economical and efficient one. From the investigation, it showed that the conventional solar still made of concrete with black fiber reinforced coating from inside is suitable for a large scale system with capacity more than $1000 \mathrm{l} /$ day. Whereas the small scale system with capacity less than $1000 \mathrm{l} /$ day, the fiber reinforced plastic multi-wick solar still is appropriate (Tiwari and Garg 1985). A potable-type solar still was designed with basin area of $0.54 \mathrm{~m}^{2}$. The daily output of fresh water was found $1.7 \mathrm{l} /$ day in the month of July. The maximum output of fresh water is $0.339 \mathrm{l} / \mathrm{h}$ at 13:00 hours. The feed surface water $330 \mathrm{ppm}$ (TDS), conductivity $1.291 \mathrm{mS} / \mathrm{cm}$, and $\mathrm{pH} 6.72$ were measured before distillation. The distilled water was found TDS of $30 \mathrm{ppm}$, conductivity $41 \mathrm{mS} / \mathrm{cm}$, and $\mathrm{pH}$ of 6.5 after distillation (Samee et al. 2007). Sodha et al. (1981) have developed new concept on multi-wick solar still to increase the productivity of still. They used a black jute cloth pieces uneven length placed one upon another and separate by polyethylene film. The entire wick remains wet due to capillary action. The width of each jute cloth is $86 \mathrm{~cm}$ and length of wick is $100 \mathrm{~cm}$. The glass thickness is $3.0 \mathrm{~mm}$. Output distilled was $2.5 \mathrm{l} / \mathrm{m}^{2}$ day. Mahdi et al. (2011) designed and experiment a wick-type solar still. They used charcoal as an absorber for their analysis and increase efficiency of $53 \%$ on clear day of summer. Naim and ElKawi (2002) investigated on basin-type solar still in which charcoal is used as an absorber medium. A similar inclined wick-type solar still was tested by SMA Maustafa et al. (1979) in which a 2.5-cm-thick black synthetic wettable mat of area $0.182 \mathrm{~m}^{2}$ was placed over a plastic sheet. The flow of water in the wick was controlled using a flow regulator and shut-off valve operated with a photocell. Another novel idea in a wick-type solar still was given by Frick and Summerfeld (1973), who suggested the use of jute cloth along the width of the still, dipped in saline water trays. The jute cloth remains wet due to capillary action and therefore avoiding the use of water distribution system. They are also reported the efficiencies achieved $40-50 \%$ with this type of still. Kabeel (2009) investigated on a concave-type wick for absorption and pyramid shaped still were normally used for condensation. The average production of still was
$4.1 \mathrm{l} / \mathrm{m}^{2}$ day. Sakthivel et al. (2010) used jute cloth on middle vertical position of the basin and another jute cloth is on the surface wall of the still. A series of experimental and theoretical studies on inclined wick-type solar stills are conducted by Mimaki et al. (1981) and Tanaka et al. (1981) in Japan. They used a black cotton towel as wick with an effective area of $1.79 \mathrm{~m}^{2}$ and glass thickness of $5 \mathrm{~mm}$. The still output recorded was $5.0 \mathrm{l} /$ $\mathrm{m}^{2}$ day at the solar global radiation of $6.67 \mathrm{kWh} / \mathrm{m}^{2}$.

Most of the research work has been done on inclined solar still but the study on inclined flat plate solar water distillation is missing in the literatures. The inclined FPSWD system gives the maximum output of fresh water with zero ppm. This system is a most efficient and cost effective from others distilled system. It can produce pure, clean fresh water on any scale from any water sources and also gives hot brine, which gives more advantages and additional efficiency. Each panel of this system is designed with an area of $3 \mathrm{~m}^{2}$, weight $17 \mathrm{~kg}$ and having a thin black fiber sheet of $2 \mathrm{~mm}$ for absorbing the input water. The front glazing is of polycarbonate thin sheet $(0.4 \mathrm{~mm})$, which is tough, dimensionally stable, high-impact resistance, good temperature capability, and expected life of 8-10 years. The cross section of such inclined FPSWD is shown in Fig. 1. The raw water enters through the top side of the panel and spread to the entire area of the black wick bed with the help of distributor at a mass flow rate of $6.6 \mathrm{~kg} / \mathrm{h}$, so that the entire area of the black sheet remains wet all the time. Solar energy is absorbed by water in the wick bed, which gets evaporated at the temperature of $60-65^{\circ} \mathrm{C}$ and later gets condensed on the inner side of the polycarbonate thin sheet and collected in the condensate channel fixed on the bottom side of the polycarbonate sheet. Remaining hot brine water at the temperature of $45-50{ }^{\circ} \mathrm{C}$ runs down at the bottom of the system.

\section{Performance analysis}

The performance of inclined FPSWD has been carried out by installing the system which consists of 10 panels, i.e., area of $30 \mathrm{~m}^{2}$ at the Out-Door Test Bed of Solar Energy Centre, MNRE (latitude: $28^{\circ} 25^{\prime} 31.2^{\prime \prime} \mathrm{N}$-longitude: $77^{\circ} 9^{\prime} 18.8^{\prime \prime} \mathrm{E}$ ) shown in Fig. 2. This system has been evaluated and observations were recorded on the basis of field data collected (period of $8-10 \mathrm{~h}$ ) in the month of winter and summer.

The output of fresh water achieved about $5.33 \mathrm{l} / \mathrm{m}^{2}$ day at the radiation $5.6 \mathrm{kWh} / \mathrm{m}^{2}$. It is also observed that, the inlet water was $350 \mathrm{ppm}$ before distillation and distilled water was found at zero ppm. In this experiment, the temperature of the hot water, cover sheet temperature were measured with thermocouples.

To simplify the performance, some assumptions and nomenclature are made in this paper. 
a

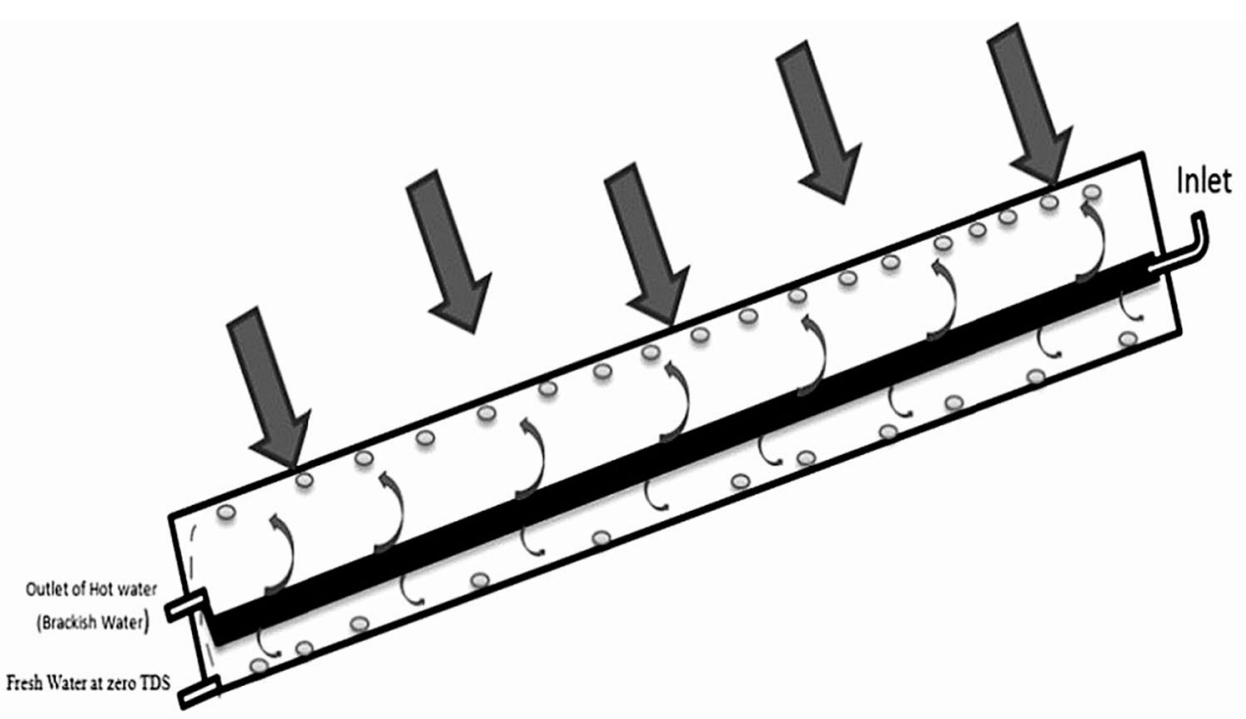

b

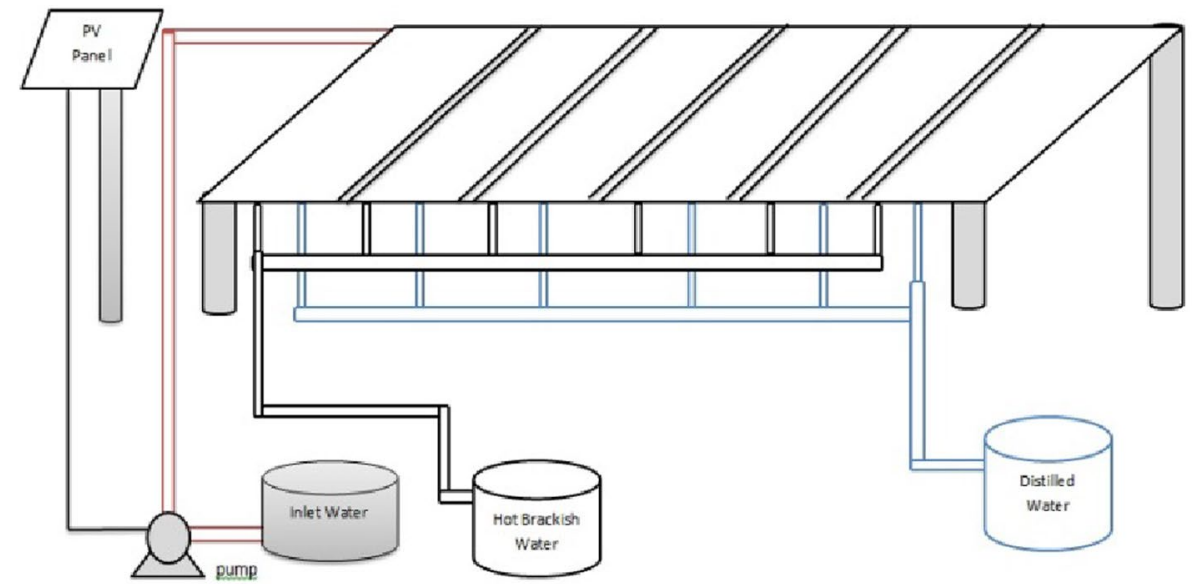

Fig. 1 a Solar flat plate collector cum distillation. b Schematic diagram of inclined solar flat plate water distillation system

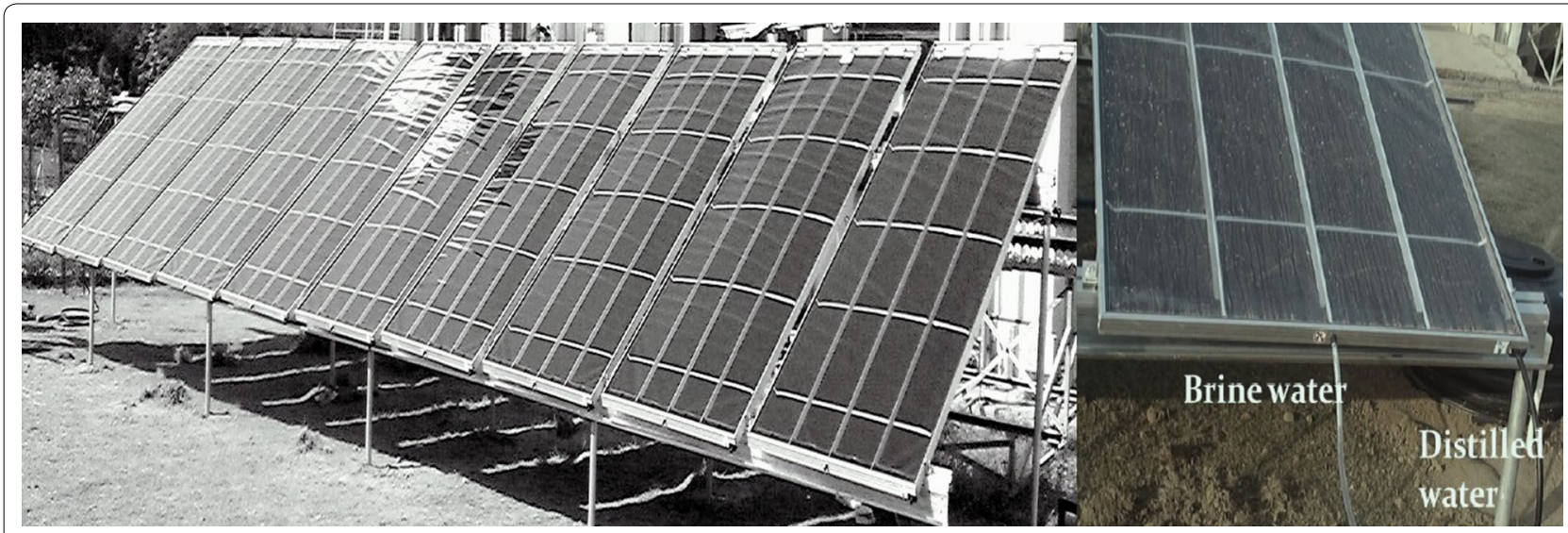

Fig. 2 Experimental setup of flat plate-type solar water distillation system 
The system is vapor leakage proof. Drunkle procedure is summarized by Tiwari et al. (2003). According to this procedure, the hourly evaporation per square meter from solar distillation is

$$
Q_{\mathrm{ew}}=0.0163 \cdot h_{\mathrm{cw}}\left(P_{\mathrm{w}}-P_{\mathrm{ps}}\right),
$$

where $h_{\mathrm{cw}}\left(\mathrm{kW} / \mathrm{m}^{2}{ }^{\circ} \mathrm{C}\right)$ is convective heat transfer coefficient from water surface to polycarbonate sheet.

The saturation water vapor pressure $(\mathrm{kPa})$ is expressed as

$$
\begin{aligned}
P_{\mathrm{w}}=100 & \left(0.004516+0.0007178 t_{\mathrm{w}}-2.649\right. \\
& \left.\times 10^{-6} t_{\mathrm{w}}^{2}+6.944 \times 10^{-7} t_{\mathrm{w}}^{3}\right),
\end{aligned}
$$

where $t_{\mathrm{w}}$ is temperature of water in ${ }^{\circ} \mathrm{C}$.

And, the saturation water vapor pressure of polycarbonate sheet is defined

$$
\begin{aligned}
& P_{\mathrm{ps}}= 100\left(0.004516+0.0007178 t_{\mathrm{ps}}-2.649\right. \\
&\left.\times 10^{-6} t_{\mathrm{ps}}^{2}+6.944 \times 10^{-7} t_{\mathrm{ps}}^{3}\right) .
\end{aligned}
$$

The instantaneous efficiency is expressed as

$$
\eta_{\mathrm{i}}=\frac{Q_{\mathrm{ew}}}{G_{t}},
$$

where $G_{t}$ is global radiation in $\mathrm{kWh} / \mathrm{m}^{2}$ per day.

Table 1 Amount of distilled water and hot brine water obtained from testing

\begin{tabular}{llll}
\hline SI. no. & $\begin{array}{l}\text { Distilled water }(\mathrm{l} / \mathbf{h} \\
\left.\text { per } \mathbf{~}^{\mathbf{2}}\right)\end{array}$ & $\begin{array}{l}\text { Hot brine water }(\mathrm{I} / \mathbf{h} \\
\left.\text { per } \mathbf{~}^{\mathbf{2}}\right)\end{array}$ & $\begin{array}{l}\text { Global radia- } \\
\text { tion }\left(\mathbf{k W h} / \mathbf{m}^{\mathbf{2}}\right)\end{array}$ \\
\hline 1. & 0.67 & 1.53 & 6.2 \\
2. & 0.58 & 1.62 & 5.6 \\
3. & 0.49 & 1.71 & 5.01 \\
4. & 0.37 & 1.83 & 3.78 \\
5. & 0.42 & 1.78 & 4.37 \\
\hline
\end{tabular}

\section{Results and discussions}

The performance has been analyzed for the period of $9 \mathrm{~h}$ in day times, i.e., 9:00 to 17:00 hours. It is observed that, during the performance testing of inclined FPSWD, average field data on different parameters namely temperature of cover sheet, hot brackish water $\left({ }^{\circ} \mathrm{C}\right)$, tilted global radiation $\left(\mathrm{kWh} / \mathrm{m}^{2}\right)$, wind speed $(\mathrm{m} / \mathrm{s})$, ambient temperature, generation of fresh water, and hot brackish water have been recorded. As seen in Table 1, the fresh water generation increases as the tilted global radiation increase. The fresh water has been achieved around $5.2 \mathrm{l} /$ $\mathrm{m}^{2}$ day at global radiation of $6.2 \mathrm{kWh} / \mathrm{m}^{2}$. The average temperature of hot water (brackish water) is $47^{\circ} \mathrm{C}$ at the ambient temperature of $24^{\circ} \mathrm{C}$ as shown in Table 2 .

The fresh water output is $4.73 \mathrm{l} /$ day $\mathrm{m}^{2}$ with an efficiency of distillation system $45.1 \%$.

Figure 3 represents the comparison between the temperatures of hourly variation on polycarbonate sheet, brackish water with respect to tilt global radiation and ambient temperature. It is seen that the polycarbonate sheet and absorber temperature increase with time increases toward the noon time (i.e., availability of global radiation) and started decrease in the same pattern due to decrease the solar global radiation on the polycarbonate sheet according to changing of day time. Figure 4 shows the hourly variation of output of distilled water with respect to global radiation and wind speed. The variation of output is dependent upon global radiation and wind speed.

\section{Conclusion}

The system generates both fresh water and hot water at the same time. Several parameters such as solar tilt global radiation, hot water temperature, flow rate

\begin{tabular}{|c|c|c|c|c|c|c|c|}
\hline SI. no. & Time & $\begin{array}{l}\text { Temperature of hot } \\
\text { water }\left(T_{0},{ }^{\circ} \mathrm{C}\right)\end{array}$ & $\begin{array}{l}\text { Inside water tem- } \\
\text { perature }\left(T_{\mathrm{w}},{ }^{\circ} \mathrm{C}\right)\end{array}$ & $\begin{array}{l}\text { Outer cover sheet } \\
\text { temperature }\left({ }^{\circ} \mathrm{C}\right)\end{array}$ & $\begin{array}{l}\text { Ambient } \\
\text { temperature }\left(T_{\mathrm{i}},{ }^{\circ} \mathrm{C}\right)\end{array}$ & $\begin{array}{l}\text { Wind } \\
\text { speed }(\mathrm{m} / \mathrm{s})\end{array}$ & $\begin{array}{l}\text { Fresh water } \\
\left(\mathrm{I} / \mathrm{h} / \mathrm{m}^{2}\right)\end{array}$ \\
\hline 1. & 9:00 & 38 & 50 & 41 & 2.8 & 2.8 & 0.234 \\
\hline 2. & $10: 00$ & 42 & 52 & 46 & 24.3 & 4.2 & 0.396 \\
\hline 3. & $11: 00$ & 50 & 59 & 53 & 24.7 & 4.6 & 0.528 \\
\hline 4. & $12: 00$ & 51 & 64 & 55 & 25.8 & 3.8 & 0.785 \\
\hline 5. & $13: 00$ & 52 & 65 & 56 & 28.7 & 3.1 & 0.799 \\
\hline 6. & $14: 00$ & 51 & 62 & 56 & 27.9 & 1.8 & 0.687 \\
\hline 7. & $15: 00$ & 49 & 60 & 55 & 25 & 1.6 & 0.623 \\
\hline 8. & $16: 00$ & 44 & 53 & 47 & 23.8 & 1.7 & 0.391 \\
\hline 9. & $17: 00$ & 46 & 51 & 48 & 23.5 & 1.72 & 0.294 \\
\hline
\end{tabular}
of water distillation, and flow rate of hot brackish water were investigated. The generation of fresh water achieved up to $6.03 \mathrm{l} /$ day per $\mathrm{m}^{2}$ on global radiation

Table 2 Hourly variation of temperature of hot water, inside water temperature, outer cover sheet temperature, ambient temperature, and fresh water generation 


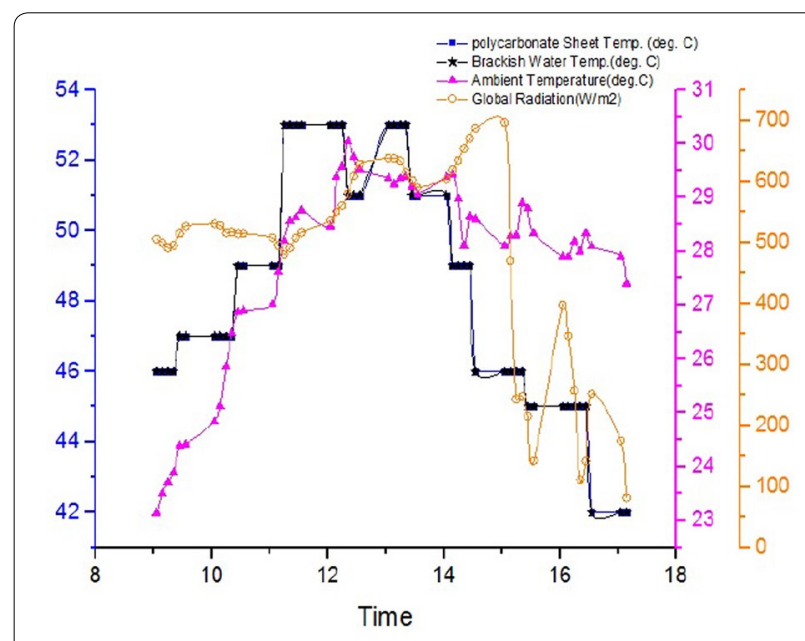

Fig. 3 Hourly variation of experimental various temperature of solar distillation system in 22nd March

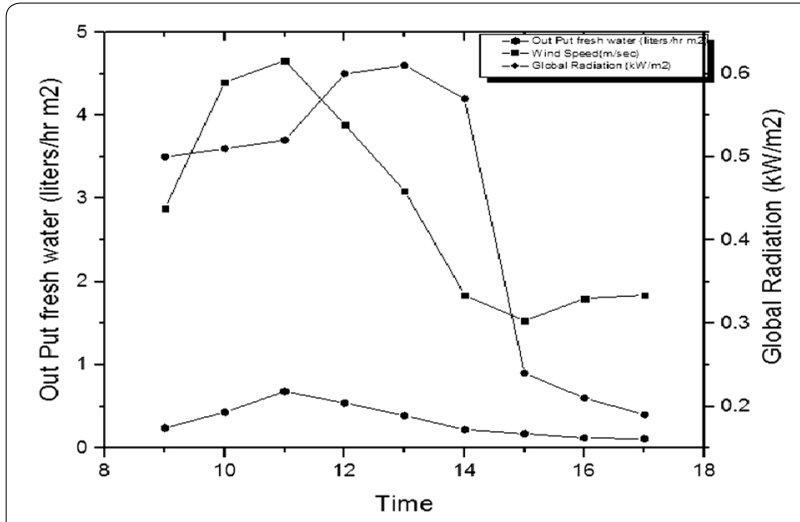

Fig. 4 Hourly variation of distil water w.r.t global radiation and wind speed

$6.2 \mathrm{kWh} / \mathrm{m}^{2}$ at ambient temperature of $23{ }^{\circ} \mathrm{C}$. The system is especially environmentally friendly that produce minimum waste products and improves the quality of life of inhabitants living in rural areas. It is especially useful for domestic household, remote areas, and defence establishment which require both fresh water for drinking.

\section{Authors' contributions}

US carried out the reviewed of the research papers, which is related to the whole research paper and participate in the sequence alignment and drafted the manuscript, and performance testing of the inclined flat plate-type distillation system. SKS suggested the paper alignment and content part of the research paper and also participated the critical analysis of the research paper. All authors read and approved the final manuscript.

\section{Author details}

1 National Institute of Solar Energy, Ministry of New and Renewable Energy, Govt. of India, Faridabad Road, Gurgaon 122003, Haryana, India. ${ }^{2}$ Delhi Technological University, Bawana Road, New Delhi, India.

\section{Acknowledgements}

Dr. N.B.Raju, contributed towards the article by making substantial contributions to conception. He was involved in drafting the manuscript or revising it critically for important intellectual content, but does not meet the criteria for authorship.

\section{Competing interests}

The authors declare that they have no competing interests.

Received: 28 March 2015 Accepted: 28 January 2016

Published online: 18 February 2016

\section{References}

Drinking water quality in rural India: issues and approach, http://www.wateraid.org/ /media/Publications/drinking-water-quality-rural-india.pdf. Accessed 11 July 2014.

Frick, G., \& Sommerfeld, J. V. (1973). Solar stills of inclined evaporating cloth. Solar Energy, 14, 427-430.

Gomkale, S. D. (1988). Operational experience with solar stills in an Indian village and their contribution to the drinking water supply. Desalination, 69, 177-182.

Kabeel, A. E. (2009). Performance of solar stills with a concave wick evaporation surface. Energy, 34, 1504-1509.

Kumar, C. P. Fresh water resources: a perspective. http://www.angelfire.com/ bc/nihhrrc/documents/fresh.html. Accessed 10 Nov 2014.

Mahdi, J. T., Smith, B. E., \& Sharif, A. O. (2011). An experimental wick-type solar still system design and construction. Desalination, 267, 233-238.

Ministry of New and Renewable Energy. (2011). Market assessment of solar water heating system. Delhi, India.

Mimaki, M., Tanaka, K., \& Watanabe., K. (1981). The performance of solar stills. Energy Developments in Japan, 3, 207-225.

Moustafe, S. M. A., Brusewotz, G. H., \& Farmer, D. M. (1979). Direct use of solar energy for water desalination. Solar Energy, 22, 141-148.

Naim, M., \& ElKawi, M. A. (2002). Non-Conventional solars stills. Part 1. non conventional solar stills with charcoal particles as absorber medium. Desalination, 153, 55-64.

Policy Phase-I \& Phase-II, 2011-12. Jawaharlal Nehru National Solar Mission of India.

Reddy, M. S., Chandra, D. J., Sehgal, H. K., Sabberwal, S. P., Bhargava, A. K., \& Chandra, D. J. (1983). Performance of a multiple-wick solar still with condenser. Applied Energy, 13, 15-21.

Sakthivel, M., Shanmugasundaram, S., \& Alwarsamy, T. (2010). An experimental study on a regenerative solar still with energy storage medium-Jute cloth. Desalination, 264, 24-31.

Samee, M. A., Mirza, U. K., Majeed, T., \& Ahmad, N. (2007). Design and performance of a simple single basin solar still. Renewable and Sustainable Energy Reviews, 11, 543-549.

Sodha, M. S., Kumar, A., Tiwari, G. N., \& Tyagi, R. C. (1981). Simple multiple wick solar still: Analysis and performance. Solar Energy, 26, 127-131.

Tanaka, K., Yamashita, A., \& Watanabe, K. (1981). Experimental and analytical study of the tilted wick type solar still. Solar World forum. Proceeding ISES Congress, pp.1087-1091.

Tiwari, G. N., \& Garg, H. P. (1985). Studies on various design of solar distillation systems. Solar and Wind Technology, 1, 161-165.

Tiwari, G. N., Singh, H. N., \& Tripathi, R. (2003a). Present status of solar distillation. Solar Energy, 75, 367-373.

Tiwari, G. N., Singh, H. N., \& Tripathi, R. (2003b). Present status of solar distillation. Solar Energy, 75(5), 367-373. 